\title{
Enhanced Read Range Tattoo RFID Tags
}

\author{
Dumtoochukwu O. Oyeka, John C. Batchelor, Badredin M. Turki \\ School of Engineering and Digital Arts, University of Kent, \\ Canterbury, Kent, CT2 7NT, United Kingdom.
}

\begin{abstract}
Transfer Tattoo RFID tags are described for person locating scenarios. The technology considered is Radio Frequency Identification (RFID) at the UHF Band where it is possible to obtain wireless connection over distances of several meters using passive, or battery assisted transfers. The tags have the profile of tattoos and can be mounted straight onto the skin. Promising results for enhancing read distances, possibly to tens of meters, have been obtained using very thin battery technologies.
\end{abstract}

\section{INTRODUCTION}

Epidermal systems using low power or passive wireless communications are a new development with particular challenges. Firstly, systems directly on-skin must be biocompatible and have the appropriate elasticity and porosity to avoid damage to the body surface. Additionally, the high losses associated with biological tissues must be overcome by transponders using ultra-low power, or entirely passive architectures. As a consequence, UHF RFID tags mounted onskin typically have efficiencies of $-11 \mathrm{dBi}$ or lower and this significantly impacts on the expected read ranges obtainable. In this work, a tag designed as a temporary tattoo transfer is developed for use with a Battery Assisted Transponder (BAT) and the expected enhanced read ranges are presented compared to an entirely passive transponder.

\section{TRANSFER TATTOO TAGS}

The designs presented are derived from [1] and are suitable for fabrication by printing processes such as conducting inkjet printing, [2]. The ink consists of a liquid vehicle containing silver nano-particles in a suspension deposited on proprietary transfer tattoo paper [3] and heat cured so that the suspending compound evaporates which enables conducting contact to be facilitated between the silver particles [4]. These tags are mounted directly on the skin and consist of a thin polymer layer carrying a thin conducting ink pattern. Overlaying a design resembling a conventional tattoo would not be problematic. At the prototype stage, the tag may be etched in copper on a thin polyester film and the transponder chip may be soldered or pressure connected to the tag.

Using reader equipment licensed for European use, the tag typically reads at $60-100 \mathrm{~cm}$ in the European Union (EU) UHF RFID band when a passive transponder with a turn-on power $\left(P_{\mathrm{to}}\right)$ of about $-15 \mathrm{dBm}$ is connected. Such a read range could be useful in short range applications, for instance, for portal based readers or for bed bound patients, though there are many situations where longer read ranges would be advantageous.
Therefore, this work indicates how the tattoo read range can be further increased if the tag if operated with an active, battery assisted transponder.

\section{BATTERY ASSISTED TATTOO TAGS}

The BAT chip was provided by EM Ltd. [5]. Battery energy is not used by the chip in the return wireless link to the reader, but the transponder receiver sensitivity is increased to different levels according to the chip operational mode. The sensitivities of the four modes are: $-17,-22,-28$ and $-31 \mathrm{dBm}$ respectively. This results in significant read range enhancements at the cost of accommodating a battery on the tag and compromising the low profile and active lifespan. To reduce the impact on the tag profile, the battery was a $0.7 \mathrm{~mm}$ thick technology marketed by Enfucell [6], and which is shown connected to the tattoo tag in Fig. 1. The tattoo tag dimension is $64 \mathrm{~mm} \times 20 \mathrm{~mm}$ with a slot dimension of $19.5 \mathrm{~mm}$ $\mathrm{x} 1.5 \mathrm{~mm}$.

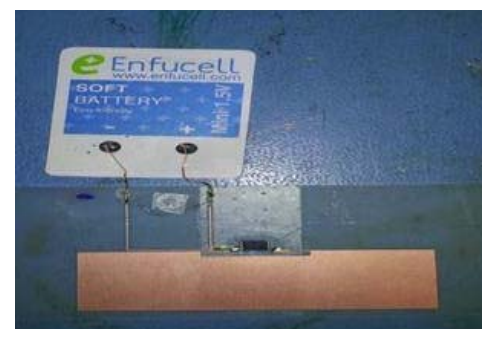

Fig. 1. Battery assisted transfer tattoo RFID tag.

Fig. 2 shows measured read ranges using the EM4325 battery assisted transponder in its passive mode (no battery connected) $P_{\text {to }}=-17 \mathrm{dBm}$ and also in its most sensitive active mode $P_{\text {to }}=-31 \mathrm{dBm}$. The tag was measured for both sensitivities on the skin of a volunteer's arm, and in the $31 \mathrm{dBm}$ active mode when isolated in free space. The read ranges were automatically extrapolated from a calibrated received power measurement using Voyantic TagformanceLite equipment, [7]. Across the UHF RFID bands in Fig.2, in the $-31 \mathrm{dBm}$ sensitivity mode, the tag reads at a distance of more than $12 \mathrm{~m}$ in air and, when on-skin, the range improves about 4 times comparing the active mode with the passive $-17 \mathrm{dBm}$ sensitivity mode. 


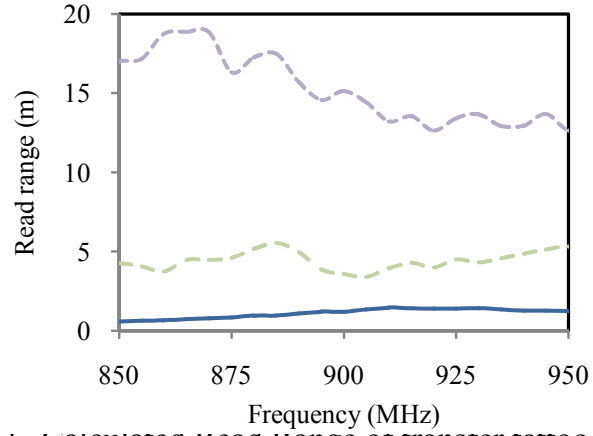

Fig. L. Lalculated Kead Kange or transter tattoo BA I tag. Solid line: Active Tag without battery; dot-dash line: Active tag with battery on arm; dash: Active tag with battery on air.

\section{INCREASED EIRP PERFORMANCE}

Predictions based on the well-known RFID range equation [8] show that potential enhancements in read range can be expected in line with the data in Table I when the reader EIRP is increased. Although EIRP is strictly controlled, there are scenarios, for instance first responders in critical situations, where higher values may be permissible. The read range columns of Table I corresponding to tag transponder turn-on powers $\left(P_{\text {to }}\right)$ of $-15,-17,-22,-28$ and $-31 \mathrm{dBm}$ relate to a passive NXP chip, and the EM4325 BAT chip in its 4 possible sensitivity modes respectively. The reader power was $0.56 \mathrm{~W}$ in all cases and calculations were taken at the European band of $868 \mathrm{MHz}$. Ranges were obtained for standard reader antenna gains of 4.4 and $6.5 \mathrm{dBi}$, which produce the EU and US EIRPs respectively. Other considered reader antenna gains were obtained from truncated and circular gridded parabolic dishes with gains between 10 and $23 \mathrm{dBi}$ [9]. Although the data is theoretical, it matches well with measurement at 4.4 and $6 \mathrm{dBi}$ gain and significant range enhancements can be expected for passive and battery assisted tags.

\section{CONCLUSIONS}

Providing battery assistance to RFID BAT chips allows the read ranges to be increased substantially, and ranges of $5 \mathrm{~m}$ or more may be expected. To utilize active chips it is essential to develop extremely low profile new battery technologies that can be closely integrated to the tattoos without degrading its performance. Advanced manufacturing printing technologies should be considered for fabrication to enable bespoke, extremely thin structures to be placed inconspicuously on skin. Also practical testing will be undertaken using enhanced power and read gain levels with high directivity dish antennas to assess the practical enhancements achievable for specialist applications requiring long read ranges.
TABle I. CAlculated ReAd RANGE For ENHANCED EIRP.

\begin{tabular}{|c|c|c|c|c|c|c|c|c|}
\hline \multirow{2}{*}{$\begin{array}{c}\text { Read } \\
\text { dish } \\
\text { diam- } \\
\text { eter }(m)\end{array}$} & \multirow{2}{*}{$\begin{array}{c}\text { Read } \\
\text { antenna } \\
\text { type }\end{array}$} & \multirow{2}{*}{$\begin{array}{l}\text { Read } \\
\text { dish } \\
\text { gain } \\
\text { (dBi) }\end{array}$} & \multirow{2}{*}{$\begin{array}{c}\text { Read } \\
\text { EIRP } \\
(d B W)\end{array}$} & $\begin{array}{c}P_{t o} \\
-15 \\
d B m \\
\end{array}$ & $\begin{array}{c}P_{t o} \\
-17 \\
d B m \\
\end{array}$ & $\begin{array}{c}P_{t o} \\
-22 \\
d B m\end{array}$ & $\begin{array}{c}P_{t o} \\
-28 \\
d B m\end{array}$ & $\begin{array}{c}P_{t o} \\
-31 \\
d B m\end{array}$ \\
\hline & & & & $\begin{array}{c}\text { Read } \\
\text { range } \\
(m)\end{array}$ & $\begin{array}{c}\text { Read } \\
\text { range } \\
\text { (m) }\end{array}$ & $\begin{array}{l}\text { Read } \\
\text { range } \\
(m)\end{array}$ & $\begin{array}{c}\text { Read } \\
\text { range } \\
(\mathrm{m})\end{array}$ & $\begin{array}{c}\text { Read } \\
\text { range } \\
(\mathrm{m})\end{array}$ \\
\hline- & Patch & 4.4 & $\begin{array}{c}2.0 \\
(\mathrm{EU})\end{array}$ & 0.8 & 1.0 & 1.7 & 3.4 & 4.9 \\
\hline- & $\begin{array}{c}\text { Log- } \\
\text { Periodic }\end{array}$ & 6.5 & $\begin{array}{c}4.0 \\
\text { (US) }\end{array}$ & 1 & 1.2 & 2.2 & 4.4 & 6.2 \\
\hline 0.4 & $\begin{array}{c}\text { Truncated } \\
\text { dish }\end{array}$ & 10 & 7.5 & 1.5 & 1.8 & 3.3 & 6.6 & 9.3 \\
\hline 0.6 & $\begin{array}{l}\text { Truncated } \\
\text { dish }\end{array}$ & 12 & 9.5 & 1.9 & 2.3 & 4.1 & 8.2 & 11.7 \\
\hline 0.9 & $\begin{array}{l}\text { Truncated } \\
\text { dish }\end{array}$ & 15 & 12.5 & 2.7 & 3.3 & 5.8 & 11.7 & 16.5 \\
\hline 1.2 & $\begin{array}{c}\text { Circular } \\
\text { dish }\end{array}$ & 17 & 14.5 & 3.4 & 4.1 & 7.3 & 14.7 & 20.7 \\
\hline 1.5 & $\begin{array}{l}\text { Circular } \\
\text { dish }\end{array}$ & 19 & 16.5 & 4.3 & 5.2 & 9.3 & 18.6 & 26.2 \\
\hline 1.8 & $\begin{array}{l}\text { Circular } \\
\text { dish }\end{array}$ & 21 & 18.5 & 5.3 & 6.5 & 11.7 & 23.3 & 32.9 \\
\hline 2.4 & $\begin{array}{l}\text { Circular } \\
\text { dish }\end{array}$ & 23 & 20.5 & 6.7 & 8.2 & 14.6 & 29.2 & 41.3 \\
\hline
\end{tabular}

\section{REFERENCES}

[1] M.A. Ziai and J.C. Batchelor, "Temporary On-Skin Passive UHF RFID Transfer Tag," IEEE Trans. on Antennas and Propagation, vol. 59, (10), pp. 529-551, October 2011.

[2] J.C. Batchelor, E.A. Parker, J.A. Miller, V. Sanchez-Romaguera and S. Yeates, "Injet Printing of Frequency Selective Surfaces," Electronics Letters, vol. 45, 2009, pp. 7-8.

[3] The MagicTouch. 'Temporary Tattoo Transfer Paper,' available: http://www.themagictouch.co.uk/acatalog/Temporary_Tattoo_Transfer_ Paper.html

[4] V. Sanchez-Romaguera, M.A. Ziai, D.O. Oyeka, S. Barbosa, J.S.R. Wheeler, J.C. Batchelor, E.A. Parker and S. Yeates, "Towards Injet Printed Low Cost Passive UHF RFID Skin Mounted Tattoo Paper Tags Based on Silver Nanoparticle Inks," Journal of Chemistry C, vol. 1, (39), 2013, pp. 6395-6402.

[5] EM, 'Battery Assisted Transponder Chip'. available: http://www.emmicroelectronic.com/products/rf-identification-security/ epc-and-uhf-ics/em4325

[6] Enfucell. 'Thin Batteries'. available: http://www.enfucell.com/ softbattery

[7] Voyantic RFID Characterization Equipment. 'VoyanticLite'. available: http://www.voyantic.com/index.php?trg=browse\&id=130

[8] K. Finkenzeller, "RFID Handbook," $3^{\text {rd }}$ Edition, Wiley, 2010.

[9] ZDA Communications US LCC. ' $850 \mathrm{MHz}$ Parabolic Dish Antennas'. available: http://www.zdacomm.com/850-mhz-grid-paraboilc-dishantenna- series.html 